\title{
Thioglycolic acid on the gold (111) surface and Raman vibrational spectra
}

\author{
Jian-Ge Zhou ${ }^{a}$, Quinton L. Williams ${ }^{a}$, Ruqian $\mathrm{Wu}^{b}$, \\ ${ }^{a}$ Department of Physics, Atmospheric Sciences, and Geoscience, \\ Jackson State University, Jackson, MS 39217, USA \\ ${ }^{b}$ Department of Physics and Astronomy, \\ University of California, Irvine, California 92697-4575, USA
}

\begin{abstract}
The interaction of thioglycolic acid $\left(\mathrm{HSCH}_{2} \mathrm{COOH}\right)$ with the $\mathrm{Au}(111)$ surface is investigaged, and it is found that at the low coverage the molecule lies down on the substrate. If the mercaptanhydrogen atom is eliminated, the resulting $\mathrm{SCH}_{2} \mathrm{COOH}$ molecule is randomly oriented on the surface. If the carboxylic acid group in the $\mathrm{HSCH}_{2} \mathrm{COOH}$ molecule is deprotonated instead, the $\mathrm{HSCH}_{2} \mathrm{COO}^{-}$molecule lies down on the surface. However, when the mercaptan-hydrogen atom in the $\mathrm{HSCH}_{2} \mathrm{COO}^{-}$molecule is removed, the resulting $\mathrm{SCH}_{2} \mathrm{COO}^{-}$molecule rises up to a certain level on the substrate. The calculated Raman vibrational spectra decipher which compounds and atomic displacements contribute to the corresponding frequencies. We thus propose a consistent mechanism for the deposition of thioglycolic acid on the $\mathrm{Au}(111)$ surface.
\end{abstract}

PACS numbers: 68.43.Bc, 61.43.Bn, 73.20.Hb 


\section{INTRODUCTION}

Self-assembled monolayers (SAMs) have attracted considerable attention as model systems for many fundamental and technological investigations ${ }^{1}$. The thiol and thiolate-based SAMs have broad applications on supramolecular assembly, wetting, tribology, corrosion inhibition, lithography, chemical and biochemical sensors, optics, and immobilization of DNA, because of both their simplicity and stability. In particular, SAMs can simulate a biological membrane which allows adsorption of proteins to metal surfaces without denaturization ${ }^{2}-\underline{\underline{4}}$. The peptide molecules with some enzymatic activity can be deposited on metal surfaces via the thiol or thiolate linkage monolayer ${ }^{5}, \underline{6}$. The deposition of a second monolayer on the top of the first adsorbed thiol or thiolate monolayer yields a bilayer system consisting of two monomolecular films. In other words, a layer of peptide molecules can be bonded to the gold surface via the linkage monolayer formed from the thioglycolic acid $\left(\mathrm{HSCH}_{2} \mathrm{COOH}\right)^{\underline{5}-\underline{7}}$.

The chemisorption of the thioglycolic acid on the gold surface was demonstrated using surface-enhanced Raman scattering ${ }^{\frac{8}{-}}$ and ultrafast electron crystallography ${ }^{9}$. It was found when the higher portion of the carboxylic acid groups is deprotonated, the higher portion of the thioglycolic acid molecules adopts a trans conformation ${ }^{8}$. It was also observed that after 2,2'-dithiodiacetic acid is deposited on the $\mathrm{Au}(111)$, the $\mathrm{SCH}_{2} \mathrm{COOH}$ molecules are randomly oriented on the gold surface ${ }^{9}$, that is, the adsorption pattern related to the $\mathrm{SCH}_{2} \mathrm{COOH}$ is different from that corresponding to the $\mathrm{HSCH}_{2} \mathrm{COOH}$. On the other hand, the swithcable SAM under the influence of an electrical potential was observed with intentionally created room for conformational changes of the molecules ${ }^{10}$. When the external electrical potential is turned on, the hexadecanoic acid molecules $\left(\mathrm{HS}\left(\mathrm{CH}_{2}\right){ }_{15} \mathrm{COO}^{-}\right)$bend their negatively

charged $\mathrm{COO}^{-}$group towards to the positively charged gold surface ${ }^{10}$. Simulating this swithcable SAM process via the ab initio method requires a prohibitive amount of computer time, so one has to study the simple case: the $\mathrm{HSCH}_{2} \mathrm{COO}^{-}$on the $\mathrm{Au}(111)$ surface.

It was recently observed that thiol stays intact when deposited on the regular $\mathrm{Au}(111)$ surface, but the $\mathrm{S}-\mathrm{H}$ bond of the thiol is broken on the defected $\mathrm{Au}(111)$ surface $\underline{11}$.12. Upon the $\mathrm{HSCH}_{2} \mathrm{COOH}$ molecules deposit on the $\mathrm{Au}(111)$, they can either remain intact, or turn into one of the following substances: 1) $\mathrm{SCH}_{2} \mathrm{COOH}$ in the presence of the defect on the $\left.\mathrm{Au}(111)^{11,12} ; 2\right) \mathrm{HSCH}_{2} \mathrm{COO}^{-}$by increasing $\mathrm{pH}$ value ; 3) $\mathrm{SCH}_{2} \mathrm{COO}^{-}$by the defect and increasing $\mathrm{pH}$ value. To get a consistent picture of the thioglycolic acid adsorption on the 
$\mathrm{Au}(111)$, one has to examine the adsorption patterns of the $\mathrm{HSCH}_{2} \mathrm{COOH}, \mathrm{SCH}_{2} \mathrm{COOH}$, $\mathrm{HSCH}_{2} \mathrm{COO}^{-}$, and $\mathrm{SCH}_{2} \mathrm{COO}^{-}$on the $\mathrm{Au}(111)$ separately. Even some theoretical simulations on thiol or thiolate based SAMs have been carried out $\underline{13}^{2} \underline{20}$, however, there has been no first-principle calculation which provides an atomic-scale description of the $\mathrm{HSCH}_{2} \mathrm{COOH}$, $\mathrm{SCH}_{2} \mathrm{COOH}, \mathrm{HSCH}_{2} \mathrm{COO}^{-}$, and $\mathrm{SCH}_{2} \mathrm{COO}^{-}$on the $\mathrm{Au}(111)$ surface. The electronic properties for this system, such as the projected density of states (PDOS) and the charge density difference, have not been discussed. While a large variety of thiol or thiolate based SAMs has been studied, still little is known about why the $\mathrm{SCH}_{2} \mathrm{COOH}$ molecules are randomly oriented on the gold surface, and how the $\mathrm{HSCH}_{2} \mathrm{COOH}$ molecules orient on the $\mathrm{Au}(111)$. Thus theory is challenged to propose a consistent model for the thioglycolic acid adsorption process on the $\mathrm{Au}(111)$ surface.

In this contribution, we address the adsorption patterns of the $\mathrm{HSCH}_{2} \mathrm{COOH}$, $\mathrm{SCH}_{2} \mathrm{COOH}, \mathrm{HSCH}_{2} \mathrm{COO}^{-}$and $\mathrm{SCH}_{2} \mathrm{COO}^{-}$molecules on the $\mathrm{Au}(111)$ surface from first principle calculation. We present adsorption energies and geometries for these four kinds of molecules on the $\mathrm{Au}(111)$ surface at $0.25 \mathrm{ML}$, and find that they demonstrate different adsorption patterns. We calculate the partial density of states (PDOS) projected on the $\mathrm{S}$ and $\mathrm{O} 2$ atom (with an attached hydrogen, see Fig. 1) to show their relation to the adsorption patterns, and evaluate the charge-density differences to illustrates the interacting bond between the adsorbates and the $\mathrm{Au}(111)$. We also compute the Raman vibrational spectra of these four kinds of molecules adsorbed on the surface to decipher the adsorption mechanism of the thioglycolic acid on the $\mathrm{Au}(111)$ substrate. By the comparison of the experimental frequencies with the computational ones, we can identify which compounds and atomic displacements contribute to the corresponding frequencies. We thus reveal how the dissociation of the mercaptan hydrogen atom and the deprotonation of carboxylic acid group play key roles in the adsorption process, and propose a consistent mechanism for the deposition of thioglycolic acid on the $\mathrm{Au}(111)$ surface.

\section{COMPUTATIONAL METHOD}

The calculations were carried out in the slab model with periodic boundary condtions by density functional theory $(\mathrm{DFT})^{21,22}$. The electron-ion interaction has been described using the projector augmented wave (PAW) method 23,24 . All calculations have been performed by 
Perdew-Wang 91 (PW91) generalized gradient approximation ${ }^{25}$. The wave functions were expanded in a plane wave basis with an energy cutoff of $400 \mathrm{eV}$. The $k$ points were obtained from Monkhorst-Pack scheme ${ }^{26}$, and $3 \times 3 \times 1 k$ point mesh was for the geometry optimization. The optimization of the atomic geometry was performed via conjugate-gradient minimization of the total energy with respect to the atomic coordinates. The supercell consisted of five layers with each layer having $12 \mathrm{Au}$ atoms. The $\mathrm{Au}$ atoms in the top three atomic layers are allowed to relax, while those in the bottom two layers are fixed to simulate bulk-like termination ${ }^{27}$. The vacuum region comprises ten atomic layers, which exceeds substantially the extension of the thioglycolic acid molecule ${ }^{21}$. For charged systems, a uniform compensating background is incorporated to maintain the charge neutrality of the supercell ${ }^{28}$. The harmonic approximation was applied to calculate the Hessian matrix and vibrational frequencies. We calculated the gold lattice constant and found it to agree with the experimental value ${ }^{29}$ within $2.1 \%$.

\section{RESULTS AND DISCUSSION}

In this section, we discuss the adsorption pattern of the $\mathrm{HSCH}_{2} \mathrm{COOH}, \mathrm{SCH}_{2} \mathrm{COOH}$, $\mathrm{HSCH}_{2} \mathrm{COO}^{-}$, and $\mathrm{SCH}_{2} \mathrm{COO}^{-}$on the $\mathrm{Au}(111)$ substrate, respectively. The adsorption

energy of the system is defined as $E_{a d s}=E_{\text {adsorbate }}+E_{A u(111)}-E_{\text {adsorbate }+A u(111)}$. The symbol top-fcc (or top-hcp) in the following tables represents the $\mathrm{S}$ atom being on the atop site of the gold atom, but leaned toward the fcc (or hcp) hollow center, and anologously for the notations bri-fcc, bri-hcp, etc. The units for the bond length and adsorption energy are Angstrom $(\stackrel{\circ}{A})$ and eV.

\section{A. The $\mathrm{HSCH}_{2} \mathrm{COOH}$ molecule on the $\mathrm{Au}(111)$ surface}

First, let us begin with our analysis with the geometries and adsorption energies of the optimized structures for the thioglycolic acid on the $\mathrm{Au}(111)$ surface at the coverage of 0.25 ML, as displayed in Table I. Here 1.00 ML means one sulfur per three gold atoms, and 0.25ML stands for one thioglycolic acid on a gold surface with twelve gold atoms. In Table II. the entries $\theta$, tilt direct and $d_{S-A u}$ refer to the polar angle between the normal vector of the surface and the $\mathrm{S}-\mathrm{C} 2$ direction, the $\mathrm{Au}(111)$ surface region towards which the $\mathrm{S}-\mathrm{C} 2$ is 
TABLE I: The geometries and adsorption energies for the structures of thioglycolic acid on $\mathrm{Au}(111)$ at $0.25 \mathrm{ML}$. The entries $\theta$, tilt direct and $d_{S-A u}$ refer to the polar angle between the normal vector of the surface and the $\mathrm{S}-\mathrm{C} 2$ direction, the $\mathrm{Au}(111)$ surface region towards which the $\mathrm{S}-\mathrm{C} 2$ is tilted, and the shortest Au-S bond length. The entries initial and optimized site stand for the S atom attachment site before and after optimization. The maximum adsorption energy is underlined.

\begin{tabular}{|c|c|c|c|c|c|c|c|}
\hline $\begin{array}{r}\text { initial } \\
\text { site }\end{array}$ & $\theta$ & $\begin{array}{c}d_{S-A u} \\
\stackrel{\circ}{A}\end{array}$ & $\begin{array}{c}\text { optimized } \\
\text { site }\end{array}$ & $\begin{array}{c}\theta \\
\operatorname{deg}\end{array}$ & $\begin{array}{c}\text { tilt } \\
\text { direct }\end{array}$ & $\begin{array}{c}d_{S-A u} \\
\stackrel{\circ}{A}\end{array}$ & $\begin{array}{c}E_{a d s} \\
\mathrm{eV}\end{array}$ \\
\hline \multirow[t]{3}{*}{ bri } & 0 & 2.60 & bri & 2.9 & hcp & 2.97 & 0.27 \\
\hline & 45 & 2.60 & bri-fcc & 54.8 & hcp & 2.89 & 0.45 \\
\hline & 90 & 2.60 & bri & 86.9 & hcp & 3.16 & 0.47 \\
\hline \multirow[t]{3}{*}{ fcc } & 0 & 2.60 & bri-fcc & 9.7 & hcp & 2.98 & 0.32 \\
\hline & 45 & 2.60 & bri-fcc & 61.0 & hcp & 3.11 & 0.36 \\
\hline & 90 & 2.60 & top-fcc & 83.7 & hcp & 3.18 & 0.50 \\
\hline \multirow[t]{3}{*}{ hсp } & 0 & 2.60 & bri-hcp & 5.8 & fcc & 2.95 & 0.30 \\
\hline & 45 & 2.60 & bri-hcp & 54.2 & fcc & 2.87 & 0.48 \\
\hline & 90 & 2.60 & hcp & 89.4 & fcc & 3.58 & 0.44 \\
\hline \multirow[t]{3}{*}{ top } & 0 & 2.60 & top & 8.0 & hcp & 2.93 & 0.26 \\
\hline & 45 & 2.60 & top & 54.8 & hcp & 2.81 & 0.37 \\
\hline & 90 & 2.60 & top & 74.2 & fcc & 2.57 & $\underline{0.63}$ \\
\hline
\end{tabular}

tilted, and the shortest Au-S bond length, respectively. The entries initial and optimized site stand for the $\mathrm{S}$ atom attachment site before and after optimization. The columns 1-3 and 4-7 list structural data pertaining to the initial and the final optimized geometry. The maximum adsorption energy is underlined.

Table I shows the adsorption energy for the most stable structure of the $\mathrm{HSCH}_{2} \mathrm{COOH}$ on the $\mathrm{Au}(111)$ surface is $0.63 \mathrm{eV}$, and the adsorption site preferred by the sulfur atom is located at the atop site of the gold atom. This stable configuration is illustrated in Fig. 17. The polar angle between the normal vector of the surface and the S-C2 direction is 74.2 $2^{\circ}$ Fig. 19 indicates that at the low coverage, the $\mathrm{HSCH}_{2} \mathrm{COOH}$ tends to lie down ${ }^{8}$. The $\mathrm{S}-\mathrm{Au}$ bond length is $2.57 \AA$, which suggests that the bonding between the $\mathrm{S}$ atom in the 


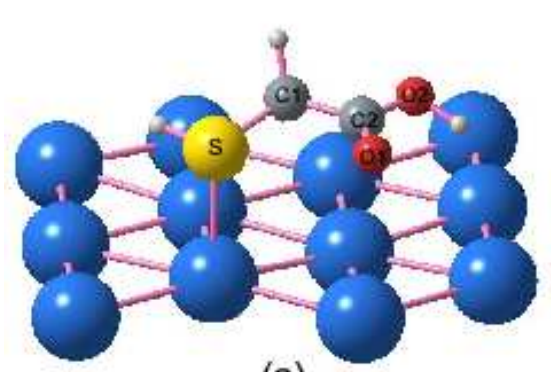

(a)

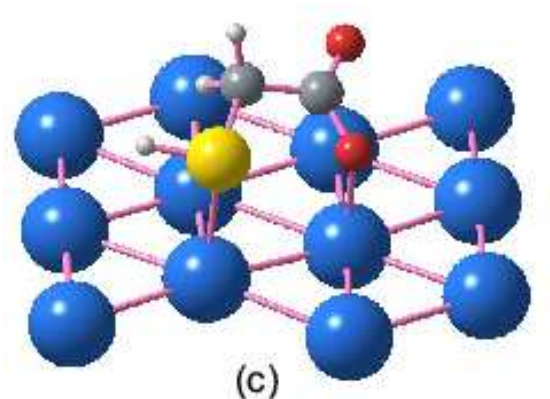

(c)

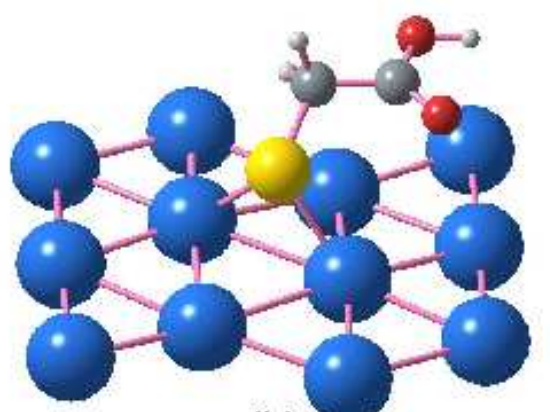

(b)

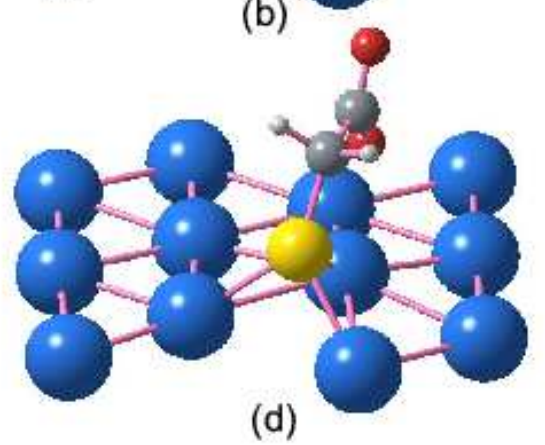

FIG. 1: (a) The thioglycolic acid $\left(\mathrm{HSCH}_{2} \mathrm{COOH}\right)$ on the $\mathrm{Au}(111)$ surface. (b) $\mathrm{SCH}_{2} \mathrm{COOH}$ on the surface. (c) $\mathrm{HSCH}_{2} \mathrm{COO}^{-}$on the surface. (d) $\mathrm{SCH}_{2} \mathrm{COO}^{-}$on the surface.

$\mathrm{HSCH}_{2} \mathrm{COOH}$ and the gold atom could be described as chemisorption $\frac{11}{2}$.

\section{B. The $\mathrm{SCH}_{2} \mathrm{COOH}$ molecule on the gold substrate}

Ruan et al. used 2,2'-dithiodiacetic acid to make SAMs on the gold surface ${ }^{9}$, then the $\mathrm{SCH}_{2} \mathrm{COOH}$ is deposited on the surface. The $\mathrm{SCH}_{2} \mathrm{COOH}$ can also be obtained from the $\mathrm{HSCH}_{2} \mathrm{COOH}$ molecule by taking away the mercaptan hydrogen atom which is initially attached to the sulfur. The adsorption pattern of the $\mathrm{SCH}_{2} \mathrm{COOH}$ molecule on the $\mathrm{Au}(111)$ surface is depicted in Table III. The adsorption energy for the most stable configuration of the $\mathrm{SCH}_{2} \mathrm{COOH}$ on the $\mathrm{Au}(111)$ surface in Table [I is $2.34 \mathrm{eV}$, and the favored adsorption site by the sulfur atom is in the hcp hollow center, but leaned to the Au-Au bridge. The corresponding structure is shown in Fig. 1 $\mathrm{b}$. The sulfur atom forms bonds with two Au atoms, and the S-Au bond length is $2.47 \AA$. The angle between the normal vector of the surface and the S-C2 direction is $68.0^{\circ}$. However, in Table $\amalg$ there are two configurations marked by \# (bri- $45^{\circ}$ and hcp- $45^{\circ}$ ) with adsorption energies $2.33 \mathrm{eV}$, which is close to the energy of the most stable one $(2.34 \mathrm{eV})$. The corresponding angles $\theta$ for these two \# 
TABLE II: The geometries and adsorption energies for the structures of the $\mathrm{SCH}_{2} \mathrm{COOH}$ molecule on the $\mathrm{Au}(111)$ at $0.25 \mathrm{ML}$.

\begin{tabular}{cccccccc}
\hline initial & $\theta$ & \multicolumn{2}{c}{$d_{S-A u}$} & optimized & $\theta$ & tilt & \multicolumn{2}{c}{$d_{S-A u}$} & $E_{a d s}$ \\
site & & $\AA$ & site & deg & direct & $\stackrel{\circ}{A}$ & eV \\
\hline bri & 0 & 2.60 & bri-hcp & 6.5 & fcc & 2.48 & 2.26 \\
& $\# 45$ & 2.60 & bri-fcc & 46.1 & hcp & 2.45 & 2.33 \\
& 90 & 2.60 & bri-fcc & 71.3 & hcp & 2.42 & 2.17 \\
\hline \multirow{2}{*}{ fcc } & 0 & 2.60 & fcc & 9.8 & hcp & 2.47 & 2.28 \\
& 45 & 2.60 & fcc & 51.0 & hcp & 2.51 & 2.17 \\
& 90 & 2.60 & bri-fcc & 71.3 & hcp & 2.50 & 2.23 \\
\hline \multirow{2}{*}{ hcp } & 0 & 2.60 & bri-hcp & 2.7 & fcc & 2.47 & 2.22 \\
& $\# 45$ & 2.60 & bri-hcp & 41.6 & fcc & 2.46 & 2.33 \\
& 90 & 2.60 & bri-hcp & 68.0 & fcc & 2.47 & $\underline{2.34}$ \\
\hline \multirow{2}{*}{ top } & 0 & 2.60 & top-fcc & 10.1 & hcp & 2.40 & 2.01 \\
& 45 & 2.60 & top-fcc & 63.0 & hcp & 2.40 & 1.89 \\
& 90 & 2.60 & top-fcc & 70.3 & hcp & 2.59 & 2.05 \\
\hline
\end{tabular}

marked configurations are $46.1^{\circ}$ and $41.6^{\circ}$, respectively. This can be interpreted as when the $\mathrm{SCH}_{2} \mathrm{COOH}$ molecules are deposited on the $\mathrm{Au}(111)$ surface, some $\mathrm{SCH}_{2} \mathrm{COOH}$ molecules lie on the substrate (see Fig. 1 b), but some of them rise up to a certain level (corresponding to \# marked configurations). Thus in the case of $\mathrm{SCH}_{2} \mathrm{COOH}$, the configurations with different tilted angles may admix, and the molecule appears to deposit on the gold substrate randomly ${ }^{9}$.

\section{The $\mathrm{HSCH}_{2} \mathrm{COO}^{-}$molecule on the surface}

When the thioglycolic acid is adsorbed on the $\mathrm{Au}(111)$ surface, its carboxylic acid group $(\mathrm{COOH})$ can be deprotonated and it becomes $\mathrm{HSCH}_{2} \mathrm{COO}^{-}$. The optimized adsorption configurations of the $\mathrm{HSCH}_{2} \mathrm{COO}^{-}$molecule on the $\mathrm{Au}(111)$ surface are described in Table III. The adsorption energies in Table III demonstrate that the sulfur atom in the 
TABLE III: The geometries and adsorption energies for the structures of the $\mathrm{HSCH}_{2} \mathrm{COO}^{-}$ molecule on the $\mathrm{Au}(111)$ surface at $0.25 \mathrm{ML}$.

\begin{tabular}{|c|c|c|c|c|c|c|c|}
\hline $\begin{array}{r}\text { initial } \\
\text { site }\end{array}$ & $\theta$ & $\begin{array}{c}d_{S-A u} \\
\stackrel{\circ}{A}\end{array}$ & $\begin{array}{c}\text { optimized } \\
\text { site }\end{array}$ & $\begin{array}{c}\theta \\
\operatorname{deg}\end{array}$ & $\begin{array}{c}\text { tilt } \\
\text { direct }\end{array}$ & $\begin{array}{c}d_{S-A u} \\
\stackrel{\circ}{A}\end{array}$ & $\begin{array}{c}E_{a d s} \\
\mathrm{eV}\end{array}$ \\
\hline \multirow[t]{3}{*}{ bri } & 0 & 2.60 & bri & 1.1 & hcp & 2.86 & 0.44 \\
\hline & 45 & 2.60 & bri & 50.6 & hcp & 2.66 & 0.67 \\
\hline & 90 & 2.60 & bri & 82.8 & hcp & 2.99 & 0.96 \\
\hline \multirow[t]{3}{*}{ fcc } & 0 & 2.60 & bri-fcc & 8.0 & fcc & 2.67 & 0.54 \\
\hline & 45 & 2.60 & bri-fcc & 65.4 & fcc & 2.74 & 0.92 \\
\hline & 90 & 2.60 & top-fcc & 77.1 & hcp & 3.38 & 0.95 \\
\hline \multirow[t]{3}{*}{ hcp } & 0 & 2.60 & hcp & 1.5 & fcc & 2.75 & 0.66 \\
\hline & 45 & 2.60 & top-hcp & 46.6 & fcc & 2.57 & 0.81 \\
\hline & 90 & 2.60 & bri-hcp & 78.0 & fcc & 3.62 & 0.83 \\
\hline \multirow[t]{3}{*}{ top } & 0 & 2.60 & top & 5.7 & hcp & 2.85 & 0.30 \\
\hline & 45 & 2.60 & top & 56.6 & hcp & 2.65 & 0.94 \\
\hline & 90 & 2.60 & top & 82.9 & hcp & 2.60 & $\underline{1.13}$ \\
\hline
\end{tabular}

$\mathrm{HSCH}_{2} \mathrm{COO}^{-}$molecule prefers to stay on the atop site of the gold atom, as indicated in Fig. 1. The corresponding adsorption energy is $1.13 \mathrm{eV}$ which is larger than that of the thioglycolic acid on the $\mathrm{Au}(111)$ surface. The S-Au bond length is around $2.60 \AA$ A and the angle $\theta$ is $82.9^{\circ}$, which means the $\mathrm{HSCH}_{2} \mathrm{COO}^{-}$molecule is lying down on the gold substrate.

\section{The $\mathrm{SCH}_{2} \mathrm{COO}^{-}$molecule on the $\mathrm{Au}(111)$ surface}

If the mercaptan- $\mathrm{H}$ atom in the $\mathrm{HSCH}_{2} \mathrm{COO}^{-}$is detached from the sulfur atom, the resulting compound is the $\mathrm{SCH}_{2} \mathrm{COO}^{-}$. Table IV shows that the sulfur atom favors the fcc hollow center with the adsorption energy $2.34 \mathrm{eV}$. The polar angle between the normal vector of the gold surface and the $\mathrm{S}-\mathrm{C} 2$ direction is $53.4^{\circ}$; so, after losing mercaptan-H atom, the $\mathrm{SCH}_{2} \mathrm{COO}^{-}$molecules begin to rise, see Fig. 11. Note that there is a \# marked configuration in Table IV, whose adsorption energy is $2.33 \mathrm{eV}$ - very closed to $2.34 \mathrm{eV}$. The 
TABLE IV: The geometries and adsorption energies for the structures of the $\mathrm{SCH}_{2} \mathrm{COO}^{-}$molecule on the $\mathrm{Au}(111)$ surface at $0.25 \mathrm{ML}$.

\begin{tabular}{cccccccc}
\hline initial & $\theta$ & \multicolumn{2}{c}{$d_{S-A u}$} & optimized & $\theta$ & tilt & \multicolumn{2}{c}{$d_{S-A u}$} & $E_{\text {ads }}$ \\
site & & $\AA$ & site & deg & direct & $A$ & eV \\
\hline bri & 0 & 2.60 & bri-hcp & 9.2 & fcc & 2.51 & 2.16 \\
& 45 & 2.60 & bri & 44.9 & hcp & 2.45 & 2.01 \\
& 90 & 2.60 & bri-fcc & 78.6 & hcp & 2.43 & 2.21 \\
\hline fcc & 0 & 2.60 & fcc & 7.8 & hcp & 2.47 & 2.14 \\
& 45 & 2.60 & bri-fcc & 53.4 & hcp & 2.49 & $\underline{2.34}$ \\
& 90 & 2.60 & bri-fcc & 83.2 & hcp & 2.49 & 2.28 \\
\hline hcp & 0 & 2.60 & hcp & 0.5 & fcc & 2.49 & 2.11 \\
& 45 & 2.60 & bri-hcp & 39.8 & fcc & 2.44 & 2.04 \\
& 90 & 2.60 & bri-hcp & 76.4 & fcc & 2.45 & 2.27 \\
\hline top & 0 & 2.60 & bri-top & 10.1 & bri & 2.54 & 1.88 \\
& $\# 45$ & 2.60 & bri-hcp & 51.8 & fcc & 2.43 & 2.33 \\
& 90 & 2.60 & top & 81.8 & fcc & 2.38 & 2.08 \\
\hline
\end{tabular}

angle $\theta$ for top $-45^{\circ}$ structure (the \# marked configuration) is $51.8^{\circ}$. The stable structures in Table IV indicate that when the $\mathrm{SCH}_{2} \mathrm{COO}^{-}$is deposited on the $\mathrm{Au}(111)$ surface, the molecule rises up to a certain levele (see Fig. 11d).

\section{E. Electronic Structures}

To understand how the dissociation of the mercaptan-hydrogen atom and the deprotonation of the carboxylic acid group play roles in the adsorption process, we calculate the partial density of states (PDOS) projected on the $\mathrm{S}$ and $\mathrm{O} 2$ atoms in the $\mathrm{HSCH}_{2} \mathrm{COOH}$, $\mathrm{SCH}_{2} \mathrm{COOH}, \mathrm{HSCH}_{2} \mathrm{COO}^{-}, \mathrm{SCH}_{2} \mathrm{COO}^{-}$molecule deposited on the $\mathrm{Au}(111)$ substrate. There are three sharp peaks in the PDOS projected on the $\mathrm{S}$ atom in the isolated $\mathrm{HSCH}_{2} \mathrm{COOH}$ molecule (Fig. 2a). The major contributions of three peaks come from $\pi, \sigma$ and $\pi^{*}$ orbitals in the S-C bond. To calibrate the Fermi level for the isolated molecule, 

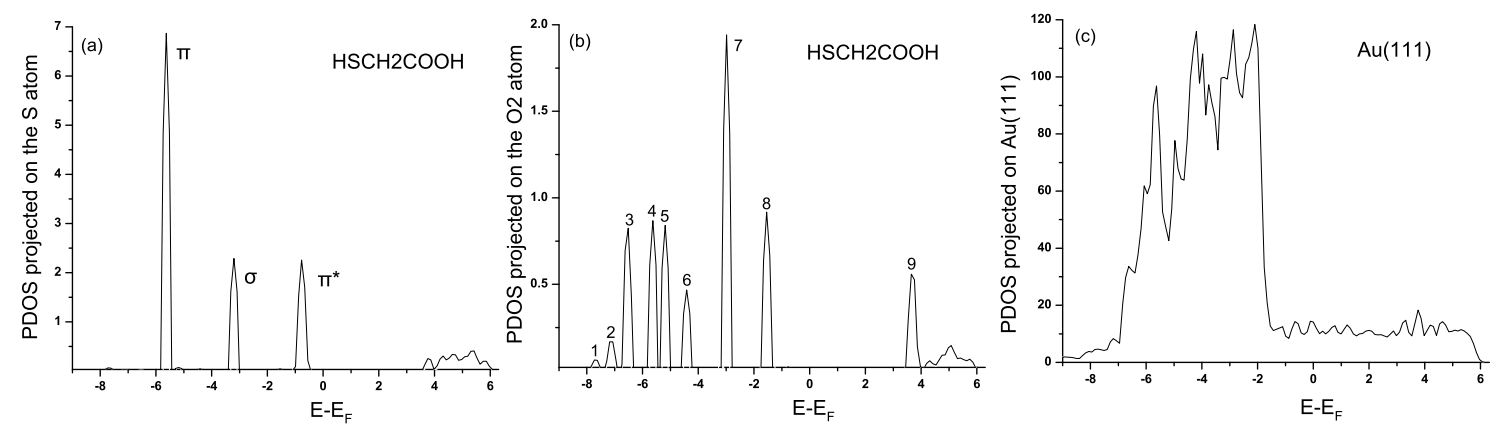

FIG. 2: (a)-(b) PDOS projected on the $\mathrm{S}$ and $\mathrm{O} 2$ atom in the isolated $\mathrm{HSCH}_{2} \mathrm{COOH}$, (c) DOS for a pure $\mathrm{Au}(111)$ surface.

in the calculation we have seperated the $\mathrm{HSCH}_{2} \mathrm{COOH}$ molecule from the gold surface by $8 \AA$ so that there is no interaction between the molecule and the substrate. The corresponding PDOS projected on the $\mathrm{S}$ atom can be regarded as that in the isolated $\mathrm{HSCH}_{2} \mathrm{COOH}$ molecule. The density of states for the pure gold surface vanishes above $6 \mathrm{eV}$ (Fig. 2 $\mathrm{c}$ ). The $\pi^{*}$ orbital is located on the right edge of the $\mathrm{Au} \mathrm{d}$ band, the $\pi$ orbital is near the left edge of the $\mathrm{Au} \mathrm{d}$ band, whereas the $\sigma$ orbital overlaps with the gold d band (Fig. 2a, Fig. 2k). Upon the $\mathrm{HSCH}_{2} \mathrm{COOH}$ molecule is deposited on the surface (Fig. 3a), the $\sigma$ and $\pi^{*}$ states disperse as a consequence of the mixing with the gold d states, whereas $\pi$ orbital remains sharp and shifts toward more negative energy. The adsorption energy of $0.63 \mathrm{eV}$ indicates that the major interaction between the sulfur in the $\mathrm{HSCH}_{2} \mathrm{COOH}$ molecule and the gold surface is not van der Waals force, so Fig. 3a might not have the signature of the weak bond.

If the mercaptan-hydrogen atom is dissociated from the $\mathrm{S}$ atom, the $\pi$ state splits indicating a stronger $\mathrm{S}-\mathrm{Au}$ bonding interaction originating from the hybridization of the $\pi$ orbital of the $\mathrm{SCH}_{2} \mathrm{COOH}$ with the gold d band (Fig. $3 \mathrm{~b}$ ). The PDOS projected on the $\mathrm{S}$ atom is insensitive to the deprotonation of the carboxylic acid group, which explains why the profiles of Fig. $3 \mathrm{a}$ and Fig. 3 $\mathrm{c}$ are similar so are Fig. $3 \mathrm{~b}$ and Fig. $3 \mathrm{~d}$. No energy gap in the PDOS projected on the $\mathrm{S}$ atom attached to the $\mathrm{Au}(111)$ surface (Fig. $3 \mathrm{a}-3 \mathrm{~d}$ ). This is because the HOMO and LUMO level of the S atom fall into the energy range of the gold d-band with a concomitant hybridization, that is, the PDOS projected on the $\mathrm{S}$ atom near the Fermi level is dominated by d-states from the $\mathrm{Au}(111)$ surface. The effect of the deprotonation of the carboxylic acid group is demonstrated by the PDOS projected on the O2 atom (Fig. 

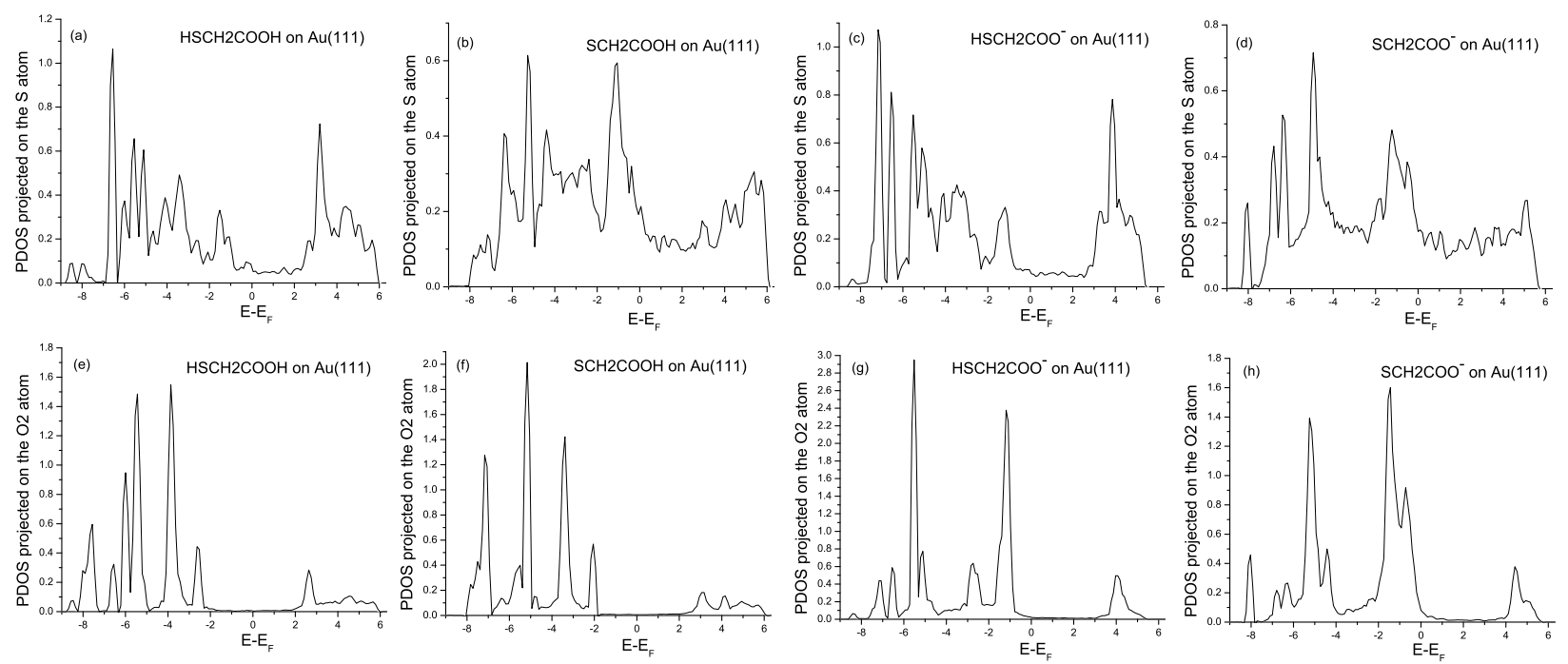

FIG. 3: (a)-(d) PDOS on the $\mathrm{S}$ in the $\mathrm{HSCH}_{2} \mathrm{COOH}, \mathrm{SCH}_{2} \mathrm{COOH}, \mathrm{HSCH}_{2} \mathrm{COO}^{-}$and $\mathrm{SCH}_{2} \mathrm{COO}^{-}$ on the surface, (e)-(h) PDOS on the $\mathrm{O} 2$ in the $\mathrm{HSCH}_{2} \mathrm{COOH}, \mathrm{SCH}_{2} \mathrm{COOH}, \mathrm{HSCH}_{2} \mathrm{COO}^{-}$and $\mathrm{SCH}_{2} \mathrm{COO}^{-}$on the surface.

3k-Fig. 3h). Nine sharp peaks are illustrated in the PDOS projected on the $\mathrm{O} 2$ atom in the isolated $\mathrm{HSCH}_{2} \mathrm{COOH}$ molecule (Fig. 2b). Upon the $\mathrm{HSCH}_{2} \mathrm{COOH}$ is deposited on the gold surface, some peaks are suppressed (Fig. $3 \mathrm{k}$ ), however, the PDOS projected on the O2 atom is insensitive to the adsorption and the dissociation of the mercaptan-hydrogen atom (Fig. 3k, Fig. 3f). Fig. 3b and Fig. 3h show that some peaks in Fig. 2b disappear and some others disperse after the carboxylic acid group is deprotonated, which indicates that the deprotonation changes the electronic states around the $\mathrm{O} 2$ atom.

To further elucidate the interacting bond between the $\mathrm{HSCH}_{2} \mathrm{COOH}, \mathrm{SCH}_{2} \mathrm{COOH}$, $\mathrm{HSCH}_{2} \mathrm{COO}^{-}, \mathrm{SCH}_{2} \mathrm{COO}^{-}$molecule and the $\mathrm{Au}(111)$ substrate, we calculate the chargedensity difference: $\Delta \rho(\vec{r})=\rho_{a d s / s u b}(\vec{r})-\rho_{\text {sub }}(\vec{r})-\rho_{a d s}(\vec{r})$, where $\rho_{\text {ads } / \text { sub }}, \rho_{\text {sub }}$, and $\rho_{\text {ads }}$ are the electron charge densities of the relaxed adsorbate-substrate system, of the clean relaxed surface, and of the isolated but adsorptionlike deformed adsorbate (without substrate), respectively. The isodensity surfaces of the charge-density difference for the structures of the $\mathrm{HSCH}_{2} \mathrm{COOH}, \mathrm{SCH}_{2} \mathrm{COOH}, \mathrm{HSCH}_{2} \mathrm{COO}^{-}$, and $\mathrm{SCH}_{2} \mathrm{COO}^{-}$on the $\mathrm{Au}(111)$ substrate are depicted in Figs. 4a-4d. In Fig. 4, we display only the surrounding part of the S-Au bond. As we know, two p-electrons of the sulfur in the $\mathrm{HSCH}_{2} \mathrm{COOH}$ molecule form a lone pair, and the region around the top of the gold is a charge depletion area ${ }^{30}$. In the configuration 
of Fig. 4 a, the sulfur atom sits on the top of the gold atom. The lone pair in the sulfur is attracted to this charge depletion region, and 0.3e is transferred from the sulfur lone pair orbital to the gold charge depletion area. Thus when the sulfur atom in the thioglycolic acid is adsorbed on the $\mathrm{Au}(111)$ (Fig. 4a), the electrostatic interaction responsible for the bonding comes from the monopole term and the dipole moments in the adsorbate and substrate ${ }^{31}$. Around the sulfur atom, there is a "ring" of accumulation of electron charge. The electrostatic interaction is dominated by the attractive ionic term modified by a repulsive dipolar term ${ }^{31}$. The sulfur atom stays on the top of the gold atom, that is, the $\mathrm{S}$ atom only forms a bond with one gold atom. If the mercaptan-hydrogen atom is detached from the sulfur (Fig. 4b), the S-Au bond is largely covalent with some ionic character ${ }^{32}$. The sulfur in the $\mathrm{SCH}_{2} \mathrm{COOH}$ forms bonds with two gold atoms of the $\mathrm{Au}(111)$ surface. The interaction between the $\mathrm{HSCH}_{2} \mathrm{COO}^{-}$and the gold surface is the similar to the thioglycolic acid case (Fig. 4k), except that the $\mathrm{O} 1$ atom form an additional bond with the gold atom. There is big depletion of electrons around the gold atom. The $p_{x}, p_{y}$ orbits in the $\mathrm{O} 1$ atom gain extra electrons, but the $p_{z}$ orbit loses some electrons. Thus, this O1-Au bonding is a convolution between the ionic bond and the covalent bond. Fig. 4d suggests that the S-Au bonds for the $\mathrm{SCH}_{2} \mathrm{COO}^{-}$is a covalent bond with some ionic character.

\section{F. The adsorption mechanism}

From the above discussion, we propose the following picture. When the $\mathrm{HSCH}_{2} \mathrm{COOH}$ molecule is adsorbed on the gold substrate, it lies down on the surface ${ }^{8}$ (Fig. 1a). When the 2,2'-dithiodiacetic acid is put on the gold surface, the $\mathrm{SCH}_{2} \mathrm{COOH}$ molecules form the SAM on the substrate ${ }^{9}$. If the thioglycolic acid is deposited on the gold surface with defects, the mercaptan hydrogen atom can be dissociated from the $\mathrm{S}$ atom and the $\mathrm{HSCH}_{2} \mathrm{COOH}$ molecule becomes $\mathrm{SCH}_{2} \mathrm{COOH}^{11,12}$. Some $\mathrm{SCH}_{2} \mathrm{COOH}$ molecules lie down on the substrate (see Fig. 1b), but others rise up to a certain level. Thus, in the case of $\mathrm{SCH}_{2} \mathrm{COOH}$, different configurations may admix and the adsorption appears to be randomly oriented $\underline{\underline{9}}$. If the carboxylic acid group in the $\mathrm{HSCH}_{2} \mathrm{COOH}$ molecule is deprotonated by increasing the $\mathrm{pH}$ value, the resulting $\mathrm{HSCH}_{2} \mathrm{COO}^{-}$lies on the surface (Fig. 10). However, when the mercaptan hydrogen atom in the $\mathrm{HSCH}_{2} \mathrm{COO}^{-}$molecule is ruptured from the sulfur, the resulting $\mathrm{SCH}_{2} \mathrm{COO}^{-}$molecule rises up to a certain level- (Fig. 11d). 


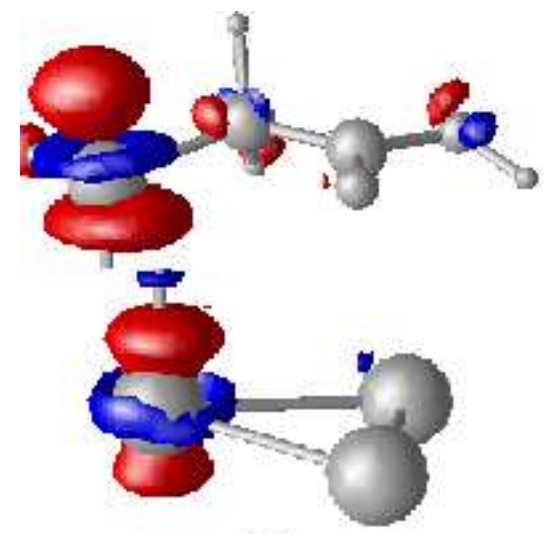

(a)

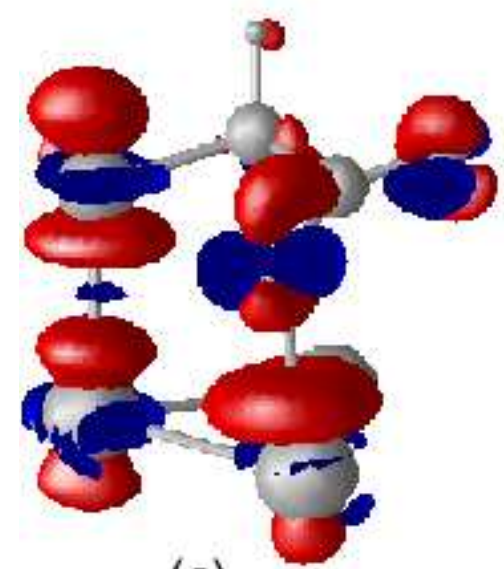

(c)

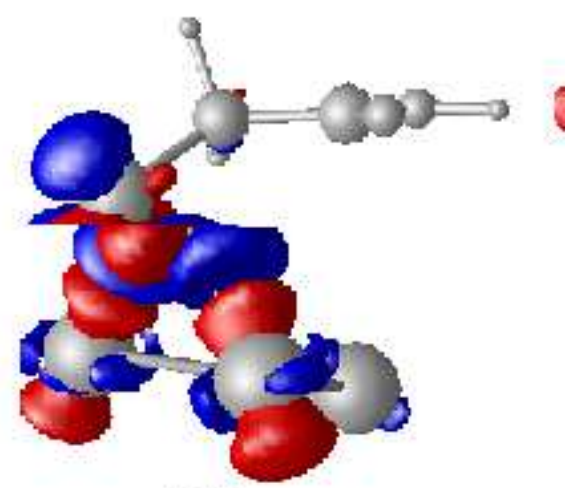

(b)

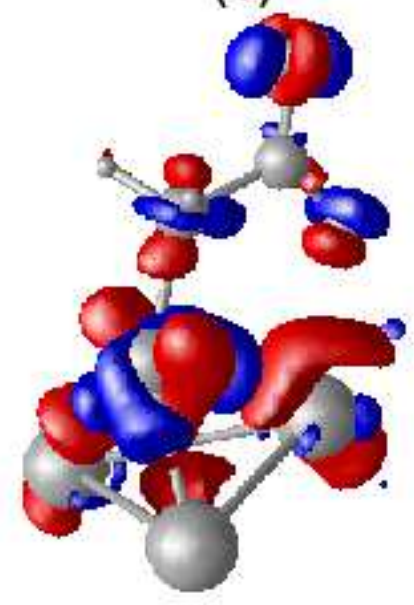

(d)

FIG. 4: The isosurfaces of the charge-density difference for (a) the $\mathrm{HSCH}_{2} \mathrm{COOH}$ adsorption on the $\mathrm{Au}(111)$ surface with blue (accumulation of electrons) and/or red (depletion of electrons) isosurface value, $\pm 0.02 e / \AA^{3}$, (b) $\mathrm{SCH}_{2} \mathrm{COOH}$ on the surface, (c) $\mathrm{HSCH}_{2} \mathrm{COO}^{-}$on the surface, and (d) $\mathrm{SCH}_{2} \mathrm{COO}^{-}$on the surface. Only three related gold atoms of the $\mathrm{Au}(111)$ surface are displayed.

\section{THE RAMAN VIBRATIONAL SPECTRA}

To support the above adsorption mechanism, we calculate the Raman vibrational spectra of the $\mathrm{HSCH}_{2} \mathrm{COOH}, \mathrm{SCH}_{2} \mathrm{COOH}, \mathrm{HSCH}_{2} \mathrm{COO}^{-}$and $\mathrm{SCH}_{2} \mathrm{COO}^{-}$adsorbed on the $\mathrm{Au}(111)$ substrate, respectively. The Raman vibrational peak frequencies $\left(\mathrm{cm}^{-1}\right)$ for experimental data and computational values for the $\mathrm{HSCH}_{2} \mathrm{COOH}, \mathrm{SCH}_{2} \mathrm{COOH}, \mathrm{HSCH}_{2} \mathrm{COO}^{-}$ and $\mathrm{SCH}_{2} \mathrm{COO}^{-}$on the $\mathrm{Au}(111)$ surface are listed in Table $\mathrm{V}$. The vibrational frequencies 
TABLE V: Raman vibrational peak frequencies $\left(\mathrm{cm}^{-1}\right)$ : Experimental data and computational values for the $\mathrm{HSCH}_{2} \mathrm{COOH}, \mathrm{SCH}_{2} \mathrm{COOH}, \mathrm{HSCH}_{2} \mathrm{COO}^{-}$and $\mathrm{SCH}_{2} \mathrm{COO}^{-}$on the $\mathrm{Au}(111)$ surface. The calculated frequencies which are the closest to the experimental ones are underlined.

\begin{tabular}{ccccccccc}
\hline frequencies & $\omega_{1}$ & $\omega_{2}$ & $\omega_{3}$ & $\omega_{4}$ & $\omega_{5}$ & $\omega_{6}$ & $\omega_{7}$ & $\omega_{8}$ \\
\hline Exp. data ${ }^{8}$ & 575 & 665 & 763 & 905 & 930 & 1387 & 1597 & 1711 \\
$\mathrm{Au}-\mathrm{HSCH}$ & $\mathrm{COOH}$ & $\underline{575}$ & 653 & $\underline{745} \underline{\underline{881}}$ & - & 1409 & - & $\underline{1733}$ \\
$\mathrm{Au}-\mathrm{SCH}_{2} \mathrm{COOH}$ & 596 & $\underline{670}$ & 725 & 872 & - & $\underline{1396}$ & - & 1738 \\
$\mathrm{Au}-\mathrm{HSCH}_{2} \mathrm{COO}^{-}$ & 592 & 619 & 734 & - & $\underline{929}$ & 1369 & 1627 & - \\
$\mathrm{Au}-\mathrm{SCH}_{2} \mathrm{COO}^{-}$ & 598 & 638 & 822 & - & 838 & 1366 & $\underline{1577}$ & - \\
\hline
\end{tabular}

were calculated for the most stable configurations at $0.25 \mathrm{ML}$. The calculated frequencies which are the closest to the experimental ones are underlined. The Raman scattering is limited to the center of the Brillion zone, and the vibrational frequencies are calculated at $\bar{\Gamma}$ point.

As shown in Fig. 5 a, the frequency $\omega_{1}\left(575 \mathrm{~cm}^{-1}, 575 \mathrm{~cm}^{-1}\right)$ (the first number stands for the experimentally measured frequency and the second one is the corresponding theoretical one, which is underlined in Table $\mathrm{V}$ ) is the vibration of the $\mathrm{S}-\mathrm{C} 1$ and the C1-C2 stretches (the $\mathrm{O} 1$ and $\mathrm{O} 2$ atoms displace slightly). The theoretical counterpart suggests that the frequency $575 \mathrm{~cm}^{-1}$ comes from the $\mathrm{HSCH}_{2} \mathrm{COOH}$ on the gold surface. Fig. $5 \mathrm{~b}$ indicates that the mode $\omega_{2}\left(665 \mathrm{~cm}^{-1}, 670 \mathrm{~cm}^{-1}\right)$ is attributed to the $\mathrm{C} 1-\mathrm{S}$ vibration of the $\mathrm{SCH}_{2} \mathrm{COOH}$ on the substrate. The frequency $\omega_{3}\left(763 \mathrm{~cm}^{-1}, 745 \mathrm{~cm}^{-1}\right)$ corresponds to the C1-S stretch of the $\mathrm{HSCH}_{2} \mathrm{COOH}$ on the surface, where the $\mathrm{O} 1$ atom displaces slightly (Fig. 55). The mode $\omega_{4}\left(905 \mathrm{~cm}^{-1}, 881 \mathrm{~cm}^{-1}\right)$ is ascribed to the stretching vibration of the $\mathrm{C}-\mathrm{COOH}$ in the $\mathrm{HSCH}_{2} \mathrm{COOH}$ molecule on the $\mathrm{Au}(111)$ (Fig. 5 $\left.\mathrm{d}\right) . \omega_{5}\left(930 \mathrm{~cm}^{-1}, 929 \mathrm{~cm}^{-1}\right)$ corresponds to the ${\mathrm{C}-\mathrm{COO}^{-}}^{-}$stretching vibration for the $\mathrm{HSCH}_{2} \mathrm{COO}^{-}$on the gold surface (Fig. 55). The frequency $\omega_{6}\left(1387 \mathrm{~cm}^{-1}, 1396 \mathrm{~cm}^{-1}\right)$ is due to the vibration of the $\mathrm{COOH}$ of the $\mathrm{SCH}_{2} \mathrm{COOH}$ on the gold surface (the C1 atom moves slightly, see Fig. 5f $)$. The mode $\omega_{7}\left(1597 \mathrm{~cm}^{-1}\right.$, $1577 \mathrm{~cm}^{-1}$ ) can be assigned to this $\mathrm{COO}^{-}$stretch in the $\mathrm{SCH}_{2} \mathrm{COO}^{-}$(Fig. 5g $\mathrm{g}$ ), which indicates that after the dissociation of the mercaptan hydrogen atom and the deprotonation of the carboxylic acid group, some original $\mathrm{HSCH}_{2} \mathrm{COOH}$ molecules on the surface have 

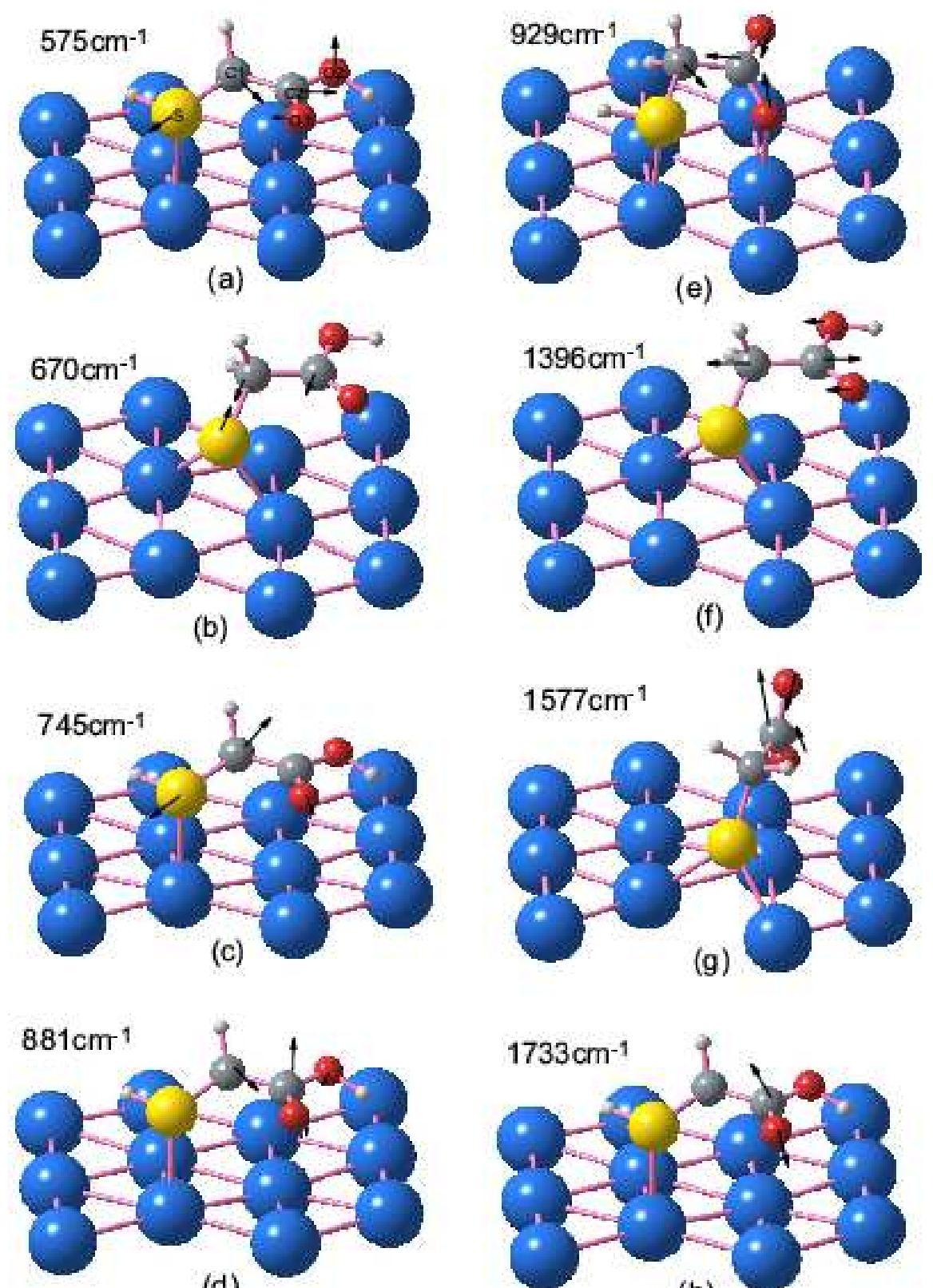

(d)

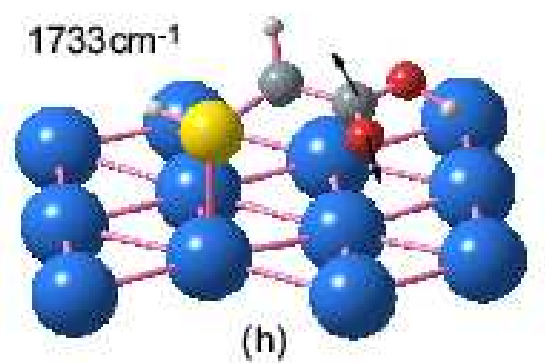

FIG. 5: (a)-(h) illustrate the calculated atomic displacements for the frequencies $\omega_{1}-\omega_{8}$.

turned into the $\mathrm{SCH}_{2} \mathrm{COO}^{-}$molecules. The frequency $\omega_{8}\left(1711 \mathrm{~cm}^{-1}, 1733 \mathrm{~cm}^{-1}\right)$ corresponds to the $\mathrm{C}=\mathrm{O}$ stretching vibration for the $\mathrm{HSCH}_{2} \mathrm{COOH}$ on the $\mathrm{Au}(111)$ substrate (Fig. 5h). Thus the above frequency comparison suggests that after the $\mathrm{HSCH}_{2} \mathrm{COOH}$ molecules deposited on the $\mathrm{Au}(111)$ surface, some stay intact on the surface, the rest have turned into $\mathrm{SCH}_{2} \mathrm{COOH}$ (via dissociation), $\mathrm{HSCH}_{2} \mathrm{COO}^{-}$(deprotonation) and $\mathrm{SCH}_{2} \mathrm{COO}^{-}$ (dissociation and deprotonation). 


\section{CONCLUSION}

We have discussed the adsorption patterns of the $\mathrm{HSCH}_{2} \mathrm{COOH}, \mathrm{SCH}_{2} \mathrm{COOH}$, $\mathrm{HSCH}_{2} \mathrm{COO}^{-}$, and $\mathrm{SCH}_{2} \mathrm{COO}^{-}$molecules on the $\mathrm{Au}(111)$ substrate by first-principle theoretical calculation. We have computed the partial density of states (PDOS) projected on the $\mathrm{S}$ and $\mathrm{O} 2$ atoms in the molecules on the $\mathrm{Au}(111)$ substrate, which display how the dissociation of the mercaptan hydrogen atom and the deprotonation of the carboxylic acid group affect the deposition and the corresponding electronic configuration. We have calculated the charge-density differences for the molecules on the $\mathrm{Au}(111)$ substrate, which illustrates various bonding characteristics. We have also studied the Raman vibrational spectra of the molecules adsorbed on the $\mathrm{Au}(111)$ substrate, and by the comparison of the experimental frequencies with the computational ones, we have identified which compounds and atomic displacements contribute to the frequencies. We have found the following adsorption mechanism for the thioglycolic acid on the $\mathrm{Au}(111)$ surface. Upon the $\mathrm{HSCH}_{2} \mathrm{COOH}$ molecules deposit on the $\mathrm{Au}(111)$, they can either remain intact, or turn into one of the following substances: 1) $\mathrm{SCH}_{2} \mathrm{COOH}$ in the presence of the defect on the $\mathrm{Au}(111)$; 2) $\mathrm{HSCH}_{2} \mathrm{COO}^{-}$ by increasing $\mathrm{pH}$ value; 3) $\mathrm{SCH}_{2} \mathrm{COO}^{-}$by the defect and increasing $\mathrm{pH}$ value. If the intact $\mathrm{HSCH}_{2} \mathrm{COOH}$ is adsorbed on the gold substrate, the molecule lies down on the surface. When the $\mathrm{SCH}_{2} \mathrm{COOH}$ molecules deposited on the $\mathrm{Au}(111)$ surface, some $\mathrm{SCH}_{2} \mathrm{COOH}$ molecules lie on the substrate, but others rise up to a certain level. Thus, in the case of $\mathrm{SCH}_{2} \mathrm{COOH}$, different configurations may admix, and the molecules appear to be deposited on the gold substrate in a random fashion. If the carboxylic acid group in the $\mathrm{HSCH}_{2} \mathrm{COOH}$ is deprotonated, the resulting $\mathrm{HSCH}_{2} \mathrm{COO}^{-}$lies down on the surface. However, when the $\mathrm{S}-\mathrm{H}$ bond in the $\mathrm{HSCH}_{2} \mathrm{COO}^{-}$is broken and the molecule is turned into $\mathrm{SCH}_{2} \mathrm{COO}^{-}$, it rises up to a certain level. 


\section{Acknowledgments}

This work is funded in part by the DoD (Grant No. W912HZ-06-C-0057) and DOE-BES (Grant No. DE-FG02-04ER15611).

1 C. Vericat, M. Vela, G. Benitez, G. Martin, X. Torrelles, R. Salvarezza, J. Phys.: Condens. Matter 18, R867 (2006).

2 K. Prime, G. Whitesides, Science 252, 1164 (1991).

3 C. Bieri, P. Ernst, S. Heyse, K. Hofmann, H. Vogel, Nat. Biotechnol. 17, 1105 (1999).

4 B. Houseman, J. Huh, S. Kron, M. Mrksich, Nat. Biotechnol. 20, 270 (2002).

5 D. Murgida, P. Hildebrandt, J. Phys. Chem. B105, 1578 (2001).

6 K. Ataka, J. Heberle, J. Am. Chem. Soc. 125, 4986 (2003).

7 M. Shimizu, K. Kobayashi, H. Morii, K. Mitsui, W. Knoll, T. Nagamune, Biochem. Biophys. Res. Commun. 310, 606 (2003).

8 A. Krolikowska, A. Kudelski, A. Michota, J. Bukowska, Surf. Sci. 532-535, 227 (2003).

9 C. Ruan, D. Yang, A. Zewail, J. Am. Chem. Soc. 126, 12797 (2004).

10 J. Lahann et al, Science 299, 371 (2003).

11 I. Rzeznicka, J. Lee, P. Maksymovych, J. Yates, Jr., J. Phys. Chem. B109, 15992 (2005).

12 J. Zhou, F. Hagelberg, Phys. Rev. Lett. 97, 045505 (2006).

13 J. Meyer, T. Bredow, C. Tegenkamp, H. Pfnuer, J. Chem. Phys. 125, 194705 (2006).

14 T. Bredow, C. Tegenkamp, H. Pfnuer, J. Meyer, V. Maslyuk, I. Mertig, J. Chem. Phys. 128, $064704(2008)$.

15 N. Gonzalez-Lakunza, N. Lorente, A. Arnau, J. Phys. Chem. C111, 12383 (2007).

16 H. Groenbeck, H. Haekkinen, J. Phys. Chem. B111, 3325 (2007).

17 H. Groenbeck, H. Haekkinen, R. Whetten, J. Phys. Chem. C112, 15940 (2008).

18 A. Franke, E. Pehlke, Phys. Rev. B79, 235441 (2009).

19 W. Zhang, B. Gao, J.L. Yang, Z. Wu, V. Carravatta, Y. Luo, J. Chem. Phys. 130, 054705 (2009).

20 P. Abufager, P. Lustemberg, C. Crespos, H. Busnengo, Langmur 24, 14022 (2008).

21 G. Kresse, J. Hafner, Phys. Rev. B47, R558 (1993). 
22 G. Kresse and J. Furtmuller, Phys. Rev. B54, 11169 (1996).

23 G. Kresse, J. Joubert, Phys. Rev. B59, 1758 (1999).

24 P.E. Blochl, Phys. Rev. B50, 17953 (1994).

25 J. Perdew, Y. Wang, Phys. Rev. B46, 6671 (1992).

26 H. J. Monkhorst, J. D. Pack, Phys. Rev. B13,5188 (1976).

27 J. Zhou, F. Hagelberg, C. Xiao, Phys. Rev. B73, 155307 (2006); J. Zhou, Q. Williams, F. Hagelberg, Phys. Rev. B76, 075408 (2007); J. Zhou, Q. Williams, F. Hagelberg, Phys. Rev. B77, $035402(2008)$.

28 G. Makov, M. Payne, Phys. Rev. B51, 4014 (1995).

29 A. Khein et al., Phys. Rev. B51, 4105 (1995).

30 O. Voznyy, J. Dubowski, J. Phys. Chem. C112, 3726 (2008).

31 M. Preuss, W. Schmidt, F. Bechstedt, Phys. Rev. Lett. 94, 236102 (2005).

32 S. Evans, A. Ulman, Chem. Phys. Lett. 170, 462 (1990). 